\title{
Action indicators for injury prevention
}

\author{
J Morag MacKay, ${ }^{1}$ Alison K Macpherson, ${ }^{2}$ lan Pike, ${ }^{3}$ Joanne Vincenten, ${ }^{1}$ \\ Rod McClure ${ }^{4}$
}

${ }^{1}$ European Child Safety Alliance, EuroSafe, Amsterdam, The Netherlands

${ }^{2}$ School of Kinesiology and Health Science, York University, Toronto, Canada

${ }^{3}$ British Columbia Injury

Research and Prevention Unit and Department of Pediatrics, University of British Columbia, Vancouver, Canada

${ }^{4}$ Monash University Accident Research Centre, Melbourne, Australia

\section{Correspondence to}

Morag MacKay, European Child

Safety Alliance, PO Box 75169,

1070AD Amsterdam, The

Netherlands; m.mackay@

childsafetyeurope.org

Accepted 14 April 2010

\section{ABSTRACT}

There is considerable confusion about the nature of indicators, their use in the injury field and surprisingly little discussion about these important tools. To date discussions of injury indicators have focused on the content and presentation of health outcome measures and on the dearth of data on exposure measures. Whereas these are valuable measures and assessing the optimal use of available routinely collected data in forming indicators is important, they do not provide sufficient information to support comprehensive prevention efforts, nor do they harness the full potential of indicators as tools to support prevention efforts. This paper provides an overview of the characteristics and uses of indicators for the field of injury prevention in order to make the case for action indicators and provide a framework for their appropriate use.

There is considerable confusion about the nature of indicators per se and their use in the injury field and surprisingly little discussion of these important tools in the peer-reviewed literature. Much of the existing debate has had a narrow focus examining only some of the difficulties in using indicators and assuming a common understanding of their purpose that probably does not exist. ${ }^{1-7}$ To date, an overview of the issues that would facilitate growth in this area has not been published, but recent renewed interest in working with indicators suggests that the time for such an overview has arrived. ${ }^{8-11}$ The renewed interest is due to a maturation of the field, an increased understanding of the nature of injury prevention efforts, and the increasing recognition by governments of the need for quantitative measures to indicate the effectiveness of injury prevention systems (policies, practices, research) and to justify and direct the appropriate allocation of resources. With the WHO call for the development of national policies to address the injury issue, the question of indicators to measure and benchmark progress has become critically important. ${ }^{12-14}$

Existing frameworks for indicators in the broader health sector have included several types of measures including those addressing driving forces, pressures, health status, exposure and actions. ${ }^{15} 16$ Historically, discussions of injury indicators have focused on measures of incidence or outcome (deaths and hospitalisations) that are usually measured through surveillance systems and have focused on relevance and validity, and noted the dearth of data on individual and population-level exposure to either hazardous circumstances or preventive interventions. ${ }^{1-5} 71718$ While these are important measures and assessing the optimal use of available routinely collected data in forming indicators is important, they do not provide sufficient information to support comprehensive prevention efforts because they do not acknowledge the systems that need to be put in place to achieve desired exposures and outcomes. ${ }^{19}$ Action indicators refer to measures of the components of the system that affect the prevalence of risk factors. Only recently has a broader perspective of indicators been taken to include these measures. ${ }^{20-22}$ This paper provides an overview of the characteristics and uses of indicators for the field of injury prevention in order to make the case for action indicators and provide a framework for their appropriate use.

\section{WHAT IS AN INJURY INDICATOR}

It is as simple as it sounds-an injury indicator is something that indicates. It is a marker placed on some part of the injury prevention system-the broader context or environment in which the injury and its prevention and management is occurring-so that you can observe and gauge any change that occurs between different points in time, or compare similar phenomena in different locations. This may be a quantitative phenomenon such as an incidence or mortality rate or a measure of exposure to a hazard; it may indicate a presence or absence such as legislation against a hazard, or it may be qualitative such as the degree of compliance with a particular policy.

While the idea of an indicator is simple, for indicators to be useful they must be selected so they point to those components of the system for which knowledge about change (or lack thereof) is essential. Selecting the appropriate indicators depends upon first being able to answer two important questions: what is it you need to monitor? why?

There are many reasons why indicators are used. They can be used to raise awareness, inform decision-makers, prioritise funding, measure progress, create a shared vision, measure the success of policies and set goals. In the field of injury prevention, using indicators is of particular importance because the systems in which injury prevention strategies are implemented are complex-multisectoral and multidimensional. Indicators to support injury prevention goals thus need to go beyond the simple outcome measures of morbidity and mortality and attempt to gauge changes in the system that need to be made to achieve an ultimate reduction in the injury burden.

\section{REQUIRED PROPERTIES OF INDICATORS}

Public health surveillance is the 'ongoing and systematic collection, analysis, interpretation and 
dissemination of health information'. ${ }^{23}$ Indicators can be developed from the health information to monitor progress towards desired goals. As such they are measurement tools, which means that to be effective they need to be scientifically sound and practical. Before selection, candidate indicators need to be examined for validity, reliability and sensitivity to change. They must be available, accessible and universally applicable. From a practical application point of view, trade-offs among the various characteristics are often necessary. ${ }^{5}$ The exact nature of trade-offs will vary based on the specific purpose and need for a given indicator.

\section{Validity}

This refers to the degree to which an indicator actually measures what it intends to measure. For example, in many countries the cause of death statistics attributed to injury are considered a valid indicator of injury mortality because it is believed that the number of deaths recorded in the mortality data systems derived from death certificates and coroners' reports truly reflects the actual number of people who have died from injury. ${ }^{17}$

\section{Reliability}

This refers to the stability and consistency of the indicator. If the same indicator is measured by different people or by different data systems, it is important that each will yield a uniform answer. The precision of the definition used for an indicator thus becomes important to ensure the same phenomenon is being measured and that the data sources are similar. Reliability becomes particularly important when indicators are used to compare and contrast progress between different jurisdictions in which measurement systems may vary. ${ }^{24}$

\section{Sensitivity to change}

This refers to an indicator's capacity to detect and measure a change considered important to the purpose of the indicator, and that can be related to the scale of measurement (eg, measuring affordability of items that cost less than $€ 100$ in increments of $€ 100$ will not indicate changes smaller than that amount). A good indicator needs to be responsive to important changes over time and differences between jurisdictions at any given point in time. ${ }^{25}$

\section{Availability}

This refers to how obtainable the data for an indicator are (eg, are data routinely collected, are they only available from ad hoc surveys or are they not collectable from a practical perspective). Often, although an indicator can be clearly defined, the data needed are not routinely available and jurisdictions are hesitant to take on new data collection unless a strong case for utility can be made. ${ }^{23} 2526$

\section{Accessibility}

This refers to the amount of effort needed to procure the data for the indicator (eg, an indictor that requires data that are extremely resource intensive to obtain or considered extremely sensitive would not necessarily make a good indicator). Some data that would support injury indicators may not be collected because of expense or political upheaval impacting on data collecting infrastructure. In the case of international comparisons, an indictor is only valuable if the data needed are available for the majority of jurisdictions being compared. ${ }^{23}$

\section{Universality}

This refers to the necessity for indicators to be compiled similarly in the different settings or jurisdictions being examined. For instance, injury data may be compiled from hospital admission/ discharge data, emergency room attendance, primary care records, or emergency ambulance attendance. Moreover, different severity scales may be used and different classifications of cause of injury. Each may be valid, but they are not comparable. For some comparisons this becomes an issue for some indicators, as they are not available for all jurisdictions being examined, making them less effective as indicators of jurisdictional variation. ${ }^{27}$

\section{IMPLICATIONS OF THE DEFINITION}

As a direct consequence of all of the above indicator characteristics, a number of implications arise. It is critically important that careful thought is put into where markers might best be placed in the injury prevention system and how they might be defined and interpreted before they are chosen.

The choice of indicators needs to be made in the context of specific purposes. There is no objective right or wrong indicator, but only one that is right or wrong in the context of the purpose within which the indicator is meant to serve. This means that there is no one universal set of injury indicators, but rather many different sets chosen across jurisdictions at many different levels for specific purposes. It is, however, possible to conceive that there might be several recognised sets that are based on needs for common purposes (eg, setting policy) at some level within similar systems. For example, a set of indicators to examine progress in reducing bicycle-related injuries among Canadian children and youth includes indicators at the policy level (presence or absence of a helmet law), indicators measuring risk factors (helmet use rates) and outcome measures (emergency department visits, hospitalisations, hospitalisations for severe injuries and deaths).

The use of indicators entails interpretation of the meaning of observed changes. This is usually done from the perspective of the rationale used to select them in the first place, which in turn is based on the system being monitored. For example, measuring the presence of a home visitation programme to educate young families on home safety interventions is subject to considerable influence from other factors. Changes in this mechanism might reflect true changes in parental education, or they may reflect the way the government is organising their mode of education delivery. A better indicator might thus be the number of families receiving targeted home safety parental education.

An indicator is not purely a passive entity. The process required to obtain an indicator can drive changes in the system being measured. For example, monitoring government policies on bicycle helmet laws may prompt governments to consider the enactment of such laws. By measuring and reporting on selected indicators you essentially create a focus for intervention activity and this has direct implications for where you place your markers on the system. As illustrated by the bicycle helmet example, if your programme goal is to achieve wide implementation of an evidence-based good practice, then the indicator(s) should focus on measuring specific progress towards that goal.

Finally, indicators can be uncollectible from a practical perspective or extremely resource intensive to collect. Ideally, the value of the information contained in an indicator should be worth the costs associated with data collection and reporting. For example, it may be impractical and cost too much to collect information on the proportion of all residential streets in which traffic calming is employed. However, collecting data from population samples may provide sufficient information upon which to base decisions and actions. Surveying the traffic-calming interventions in a limited number of randomly selected sites may thus make the data collection for this indicator more feasible. 


\section{SELECTING AND OPERATIONALISING INJURY INDICATORS}

Selecting and operationalising indicators typically follows a process of discussing possible indicators, weighing each option against a set of criteria balancing the issues of validity, reliability and sensitivity to change, in addition to issues such as data availability, accessibility and universality. Before beginning the process, there are two preceding steps that are key to selecting appropriate indicators.

The first is to describe clearly the context within which the indicators will be used. Who is the audience for the indicator information? How will they use the information and for what purpose? How does that purpose fit within the larger system in which you are operating? Justification for the selection of an indicator addresses these considerations and gives reason for its inclusion.

The second step is to address any knowledge gaps before assessing where indicators might best be placed in the system. To achieve this you need to understand how your 'intervention' programme or policy is working. This includes understanding causal relationships, any theoretical framework used and the social, political and cultural environment (system) in which you are working. Proceeding to the selection of indicators without this step increases the likelihood that you will miss identifying and marking key points in the system.

Once these issues have been addressed you can begin to examine where markers might best be placed, identify possible measures of those markers, and address some of the practical decisions involved in operationalising the measurement of the indicators. This includes examining the scientific soundness and practicality of each potential measure and coming to a decision as to its feasibility as an indicator.

The Child Safety Action Plan (CSAP) project provides a European example of this process. ${ }^{28}$ In this initiative the selection and operationalisation of action indicators at a policy level was done within the context of a nine-step process for national strategic plan development. Action indicators, including those related to the adoption of evidence-based good practice, were seen as critical drivers of all nine steps in the process. Project partners were charged with engaging national stakeholders and government in the planning process to ensure the stakeholders who would play a role in the implementation of plans were involved-this group served as the audience for the indicator information.

Indicator information was viewed as the foundation for planning, and action indicators were introduced as part of the self-assessment each country undertook of the overall environment within which child injury prevention was being conducted in their country. Previous researchers had noted large knowledge gaps when trying to understand why injury rates differed across countries. ${ }^{29} 30$ It was thus seen as critical that the indicators for CSAP cover not only traditional outcome measures, but also other key areas that would guide solution-based planning such as leadership, infrastructure and capacity to support child safety and measures of existing policy. ${ }^{28}$ The assessment of current levels of this broader set of indicators provided a way for countries to identify areas of strengths and weaknesses upon which their plan would be built, as well as the identification of gaps that could be addressed within plan development. A standardised set of indicators across the participating countries was used to compare (benchmark) progress among countries thereby encouraging the adoption and implementation of evidence-based good practice across all countries.

The selection and operationalisation of action indicators within CSAP posed several challenges. The greatest of these related to indicator validity, and included interrelated issues of specificity of case definition, the use of proxy measures and the level of detail to which the indicator refers. To address the first of these issues within CSAP particular attention was given to ensuring that the case definition for each indicator was clear and specifically captured the issue of interest. For example, when examining legislative action, the selection of the legislation of interest was based on topics identified as evidence-based good practices and used the definitions derived from that same evidence. The existence of a law requiring a certain temperature for tap water in domestic settings was not sufficient to meet the definition, which required that the law required a temperature of less than $50^{\circ} \mathrm{C}$, which European experts have agreed is a safe temperature for preventing scalds to children. The indicator definition also required that the legislation applied to all dwellings and not just new buildings. There were several CSAP action indicators developed for constructs for which there was no direct measure (eg, infrastructure to support child injury prevention), and in these circumstances we examined the literature relating to the constructs, and developed a series of proxy measures that are intended to capture aspects of the construct that are seen to be important. For example, for infrastructure we considered the proxy measures: whether there was an organisation with mandated responsibility to coordinate injury data and produce reports to support action; the existence of regular reporting on child injury deaths; the existence of a mechanism to allow the early identification of and rapid response to emerging safety hazards.

With respect to measuring the degree of action (eg, level of implementation or enforcement of a law) we found often only a crude measure could be used when a more detailed measure might have been desirable. In the absence of a prohibitive amount of research to measure actual implementation or enforcement, expert opinion was used to obtain judgement on a dichotomised measure (ie, fully implemented and/or is being fully enforced vs not fully implemented/enforced) to overcome subjective variation/error.

The reliability of the data collection process in CSAP was an important consideration because different individuals in each country collected the data. To try and minimise error we devised a clear data collection protocol, including suggested sources of information and requesting detailed information (eg, name of law, amount of fine) that required partners to go to the real source.

To ensure the CSAP indicators were sensitive to change, composite measures for important constructs were created using multiple components. For example, the leadership indicator was developed by combining 10 variables including: the presence of a lead government department/ministry for national coordination of child and adolescent safety activities; a specific contact or focal point identified for child and adolescent safety for each of the government sectors involved in the issue; injury prevention as a national priority by government; a government-led national injury prevention strategy with specific targets for children and the commitment of dedicated government funds for the development/support of national prevention programmes, research, capacity building; a national steering group or a network or organisation to coordinate activities related to child and adolescent safety. The leadership indicator score is thus sensitive to minor changes between countries and over time.

The issues of availability, accessibility and universality of indicators posed particular issues for CSAP. The procurement of the relevant information required searching into new areas (eg, legislation, standards) across many sectors, and frequently although the constructs of interest exist (eg, leadership, infrastructure), they typically are not routinely measured. These issues were addressed by the careful definition and collection of information across the 


\section{What is already known on the subject}

Indicators provide a useful tool that can be used for a number of useful purposes including informing decision-makers, prioritising funding and measuring progress.

\section{What this study adds}

This paper introduces the idea of action indicators for injury prevention to measure the components of the system that affect the prevalence of risk factors and provides a framework for their appropriate use and complement the more traditionally considered exposure and outcome indicators.

settings/jurisdictions being examined in only those areas where appropriate sources and details were available to meet indicator definitions, and in some cases examining actions on a less detailed three-point scale that could be categorically answered rather than a fine-graded scale in which the chance of missing data would have become a problem.

\section{CONCLUSION}

This paper has provided an overview of the characteristics and uses of action indicators for the field of injury prevention and provided a framework for their appropriate use. In particular, the paper has drawn attention to the many types of measures that can serve as indicators, and argued that the choice of indicator is determined by the need that it serves. The importance of the increased use of injury indicators is unequivocal. The increasing attention in the literature to the issues of what indicators to use is evidence of the growing recognition of their importance. However, the injury indicator debate could be enhanced if it began to explore a broader approach to injury indicators and considered indicators beyond the measures of injury incidence and outcome to examine indicators of exposure and, as described in this paper, action indicators at a policy level. Such a broadening of the debate might increase the utility of the suggested indicators for driving the process of injury prevention, rather than simply monitoring the outcomes. Further dialogue in the global discussion of indicators to support injury prevention might strengthen current approaches to developing and implementing effective evidence-based injury prevention policies and practices.

\section{Competing interests None.}

Contributors JMM, idea for article, literature review, drafting of article, guarantor; AKM, drafting of article; IP, drafting of article; JV, drafting of article; RM, idea for article, literature review, drafting of article.

Provenance and peer review Not commissioned; externally peer reviewed.

\section{REFERENCES}

1. Cryer CP, Jarvis SN, Edwards P, et al. How can we reliably measure the occurrence of non-fatal injury? Int J Consumer Product Saf 1999;6:183-91.

2. Cryer PC, Jarvis SN, Edwards P, et al. Why the government was right to change the 'Our Healthier Nation' accidental injury target. Public Health 2000;114:232-7.

3. Cryer C, Langley JD, Stephenson SC, et al. Measure for measure. The quest for valid indicators of non-fatal injury. Public Health 2002;116:257-62.
4. Cryer C. Injury outcome indicators - validation matters. Int J Inj Contr Saf Promot 2005; 12:219-24

5. Lyons RA, Brophy S, Pockett R, et al. Purpose, development and use of injury indicators. Int J Inj Contr Saf Promot 2005:12:207-11.

6. McClure R, Peel N, Kassulke D, et al. Appropriate indicators for injury control? Public Health 2002;116:252-6.

7. McClure RJ, Cameron CM, Purdie DM, et al. Indicators of injury burden: which types are the most important? Int J Inj Contr Saf Promot 2005;12:213-17.

8. Pike I, Piedt S, Warda L, Yanchar N, Macarthur C, Babul S, Macpherson AK. Developing injury indicators for Canadian children and youth: a modified Delphi approach. Inj Prev 2010;16:154-60.

9. Child safety action plan. http://www.eurosafe.eu.com/csi/eurosafe2006.nsf/ wwwVwContent/l3childsafetyactionplans.htm (accessed 4 0ct 2009).

10. European injury prevention indicators group, work done to support the development of the European Community Health Indicators (ECHI). http://ec.europa.eu/health/ ph_information/dissemination/echi/echi_en.htm (accessed 4 0ct 2009).

11. International Collaborative Effort for Injury Statistics (ICE). http://www.cdc.gov/nchs/ injury/advice.htm (accessed 4 Oct 2009).

12. Krug EG, Dahlberg LL, Mercy JA, et al, eds. World report on violence and health. Geneva, Switzerland: World Health Organization, 2002. http://www.who.int/ violence_injury_prevention/violence/world_report/en/index.html laccessed 4 0ct 2009).

13. Peden M, Scurfield R, Sleet D, et al, eds. World report on road traffic injury prevention. Geneva, Switzerland: World Health Organization, 2004. http://www.who. int/violence injury_prevention/publications/road traffic/world_report/en/index.html (accessed $\overline{4}$ Oct 2009).

14. Peden M, Oyegbite K, Ozanne-Smith J, et al, eds. World report on child injury prevention. Geneva, Switzerland: World Health Organization, 2008. http://whqlibdoc. who.int/publications/2008/9789241563574_eng.pdf (accessed 4 0ct 2009).

15. Briggs D. Making a difference: indicators to improve children's environmental health survey. Geneva, Switzerland: World Health Organization, 2003. http://www.who.int/ phe/children/en/cehindic.pdf (accessed 4 0ct 2009).

16. Rigby MJ, Köhler LI, eds. Child health indicators of life and development (CHILD). Report to the European Commission, September 2002. http://ec.europa.eu/health/ ph_projects/2000/monitoring/fp_monitoring_2000_exs_08_en.pdf (accessed 4 0ct 2009).

17. Cryer C, Langley JD. Developing valid indicators of injury incidence for 'all injury'. Inj Prev 2006;12:202-7.

18. Cryer C, Langley J. Developing indicators of injury incidence that can be used to monitor global, regional and local trends. Dunedin: Injury Prevention Research Unit University of Otago, 2008. www.otago.ac.nz/ipru/ReportsPDFs/OR70.pdf (accessed 4 Oct 2009).

19. Murray CJL, Frenk J. Health metrics and evaluation: strengthening the science. Lancet 2008;371:1191-9.

20. Christie N, Towner E, Cairns S, et al. Children's road traffic safety: an international survey of policy and practice. Road safety report No 47. London: Department for Transport, 2004. http://eprints.ucl.ac.uk/archive/00001211/01/2004_4.pdf (accessed 4 Oct 2009).

21. Farchi S, Molino N, Giorgi Rossi P, et al. European Road Accident Indicator Working Group. Defining a common set of indicators to monitor road accidents in the European Union. BMC Public Health 2006;6:183.

22. MacKay M, Vincenten J. Child Safety Summary Report Card for 24 Countries-2009. Amsterdam, The Netherlands: European Child Safety Alliance, Eurosafe. 2009. http://www.eurosafe.eu.com/csi/eurosafe2006.nsf/ wwwVwContent/l3childsafetyreportcards2009.htm (accessed 4 Oct 2009)

23. Holder Y, Peden M, Krug E, et al. Injury surveillance guidelines. Geneva, Switzerland World Health Organization, 2001. http://www.who.int/violence injury_prevention/ publications/surveillance/surveillance_guidelines/en/index.html (accessed Oct 2009).

24. Connor J, Langley C, Cryer C. International comparisons of injury: a compilation of reports to the New Zealand Injury Prevention Strategy Secretariat. Dunedin: Injury Prevention Research Unit University of Otago, 2007. www.cdc.gov/nchs/data/ice/ Int comp Combined 9072 \%20w.pdf (accessed 10 Dec 2008).

25. Rigby M $\overline{\mathbf{J}}$, Köhler LI, Blair $\overline{\mathrm{M}} \overline{\mathrm{E}}$, et al. Child health indicators for Europe: a priority for a caring society. Eur J Public Health 2003;13(3 Suppl):38-46.

26. Cryer C, Langley JD, Jarvis SN, et al. Injury outcome indicators: the development of a validation tool. Inj Prev 2005;11:53-7.

27. Lyons RA, Polinder S, Larsen CF, et al. Methodological issues in comparing injury incidence across countries. Int J Inj Contr Saf Promot 2006;13:63-70.

28. MacKay M, Vincenten J. Action planning for child safety: a strategic and coordinated approach to reducing the number one cause of death for children in Europe. Amsterdam: European Child Safety Alliance, Eurosafe, 2007. http://www. eurosafe.eu.com/csi/eurosafe2006.nst/wwwVwContent//3childsafetyactionplanning. htm (accessed 10 Dec 2008).

29. Towner $\mathbf{E}$, Towner J. UNICEF's child injury league table. An analysis of legislation: more mixed messages. Inj Prev 2002;8:97-100.

30. Chalmers D, Pless B. UNICEF's child injury league table: a bag of mixed messages Inj Prev 2001;7:81-2. 